University of Wollongong

Research Online

Australian Institute for Innovative Materials -

Papers

Australian Institute for Innovative Materials

$1-1-2016$

Improved cycling stability of lithium-sulphur batteries by enhancing the retention of active material with a sandwiched hydrothermally treated graphite film

Yuede Pan

University of Wollongong, yp388@uowmail.edu.au

Shulei Chou

University of Wollongong, shulei@uow.edu.au

Hua-Kun Liu

University of Wollongong, hua@uow.edu.au

SX. Dou

University of Wollongong, shi@uow.edu.au

Follow this and additional works at: https://ro.uow.edu.au/aiimpapers

Part of the Engineering Commons, and the Physical Sciences and Mathematics Commons

Research Online is the open access institutional repository for the University of Wollongong. For further information contact the UOW Library: research-pubs@uow.edu.au 


\title{
Improved cycling stability of lithium-sulphur batteries by enhancing the retention of active material with a sandwiched hydrothermally treated graphite film
}

\begin{abstract}
A new lithium-sulphur battery with a hydrothermally treated graphite film sandwiched between the separator and the sulphur cathode shows increased capacity, enhanced cycling stability and improved coulombic efficiency. After 50 cycles, a high capacity of $631 \mathrm{~mA} \mathrm{~h} \mathrm{g-1}$ is maintained, compared to $203 \mathrm{~mA}$ $\mathrm{h} \mathrm{g}-1$ for the Li-S battery with conventional configuration. Moreover, the coulombic efficiency is increased to near $100 \%$ from around $94 \%$. This improved electrochemical performance could be attributed to the new cell configuration, because the graphite film greatly retains the active material by alleviating the polysulphide shuttling problem and providing extra reaction sites for sulphur species.
\end{abstract}

\section{Keywords}

lithium, stability, cycling, film, improved, graphite, treated, hydrothermally, sandwiched, material, active, retention, enhancing, batteries, sulphur

\section{Disciplines}

Engineering | Physical Sciences and Mathematics

\section{Publication Details}

Pan, Y., Chou, S., Liu, H. \& Dou, S. (2016). Improved cycling stability of lithium-sulphur batteries by enhancing the retention of active material with a sandwiched hydrothermally treated graphite film. RSC Advances, 6 (41), 34131-34136. 


\title{
Improved cycling stability of lithium-sulphur batteries by enhancing the retention of active material with a sandwiched hydrothermally treated graphite film
}

\author{
Yuede Pan, Shu Lei Chou*, Hua Kun Liu and Shi Xue Dou \\ A new lithium-sulphur battery with a hydrothermally treated graphite film sandwiched between the separator and the \\ sulphur cathode shows increased capacity, enhanced cycling stability and improved Coulombic efficiency. After 50 cycles, a \\ high capacity of $631 \mathrm{~mA} \mathrm{~h} \mathrm{~g}^{-1}$ is mantained, compared to $203 \mathrm{~mA} \mathrm{~h} \mathrm{~g}^{-1}$ for the Li-S battery with conventional configuration. \\ Moreover, the Coulombic efficiency is increased to near $100 \%$ from around $94 \%$. This improved electrochemical \\ performance could be attributed to the new cell configuration, for the graphite film greatly retains the active material by \\ elliviating the polysulphide shuttling problem and providing extra reaction sites for sulphur species.
}

\section{Introduction}

Li-S batteries have been considered as promising nextgeneration batteries owing to their high theoretical specific capacity of $1675 \mathrm{~mA} \mathrm{~h} \mathrm{~g}^{-1}$ and energy density of $2500 \mathrm{~W} \mathrm{~h} \mathrm{~kg}^{-1}$, the abundance and low price of sulphur ${ }^{1}$. The theoretical energy density of Li-S batteries is 3 5 times higher than that of conventional lithium ion batteries ${ }^{2}$. These attractive advantages make Li-S batteries an important candidate of energy storage systems for wide applications in electric vehicles and back-up energy storage applicants for renewable and intermittent energies like solar and wind. However, compared to conventional electrode materials $\left(\mathrm{LiCoO}_{2}, \mathrm{LiFePO}_{4}\right.$, etc. $)$, a unique problem for sulphur as the cathode material is the low utilization of the active material sulphur ${ }^{3}$. First, the intrinsic high electrical resistivity of sulphur makes the active material utilization very low, particularly at high rates ${ }^{4}$. Because of the poor transport of both lithium ions and electrons, a certain percentage of the sulphur in the cathode is not able to be participating in the electrochemical reactions. This is one main reason that for a long time, the reported capacity of Li-S batteries was low until Nazar et al. reported a high-capacity Li$\mathrm{S}$ cathode of S/CMK-3 composite, prepared by a melt-diffusion method $^{5}$. Second, apart from the low utilization of sulphur in the cathode, sulphur is lost in the form of polysulphides, which are the solvable intermediate products in the transformation between the two end products of sulphur and $\mathrm{Li}_{2} \mathrm{~S}$. The intermediate polysulphides are dissolved in the ether-based liquid electrolyte and shuttle between the sulphur cathode and the lithium anode, causing quickly decay of the capacity ${ }^{6}$. To increase the active material utilization, varied approaches have been applied. For example, sulphur has been incorporated with different carbon materials ${ }^{7}$, conductive polymer $^{8}$ and metal oxides $^{9}$. Also, the interlayer strategy proves effective in decreasing the polysulphide shuttling problem ${ }^{10}$.

Here, we report a new configuration of Li-S batteries using a graphite film sandwiched between the sulphur cathode and the separator (Scheme 1). The cathode material is sulphur/Super $\mathrm{P}$ composite (S/SP). The graphite film was hydrothermally treated in order to anchor functional groups of carbonyl and carboxyl, which have strong affinity with the polysulphides. The graphite film suppresses the polysulphide shuttling problem and provides extra reaction sites for the sulphur species, thereby improves the active material utilization, the capacity and the cycling stability of the Li-S battery.

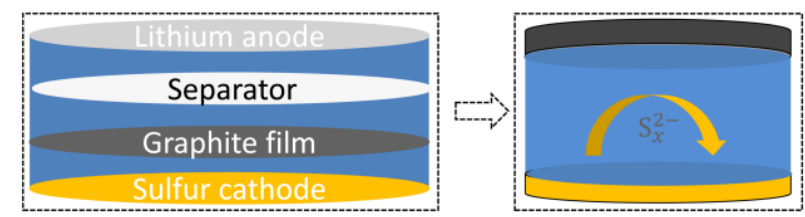

Scheme 1 A new cell configuration with a graphite film sandwiched between the sulphur cathode and the separator. The graphite film acts as a polysulphide blocking layer for retaining the active material.

\section{Experimental}

Hydrothermal treatment of the graphite film. Graphite films were ultrasonically treated in acetone, and then put into a 100 $\mathrm{mL}$ Teflon-lined stainless-steel autoclave. $50 \mathrm{~mL}$ of deionized water was added and heated at $120^{\circ} \mathrm{C}$ for $10 \mathrm{~h}$. After the hydrothermal treatment, the films were ultrasonicated in acetone and dried at 100 for $4 \mathrm{~h}$ and then put into a glove box filled with argon. Before the cells were assembled, the graphite films were soaked in the electrolyte for $24 \mathrm{~h}$.

Material characterizations. S/SP composite was prepared through the reaction between sodium thiosulphate and oxalic acid. Raman scattering experiments were performed on a JOBIN YVON HR800 Confocal Raman system with a 632.8 nm He-Ne laser. The morphology and structure of the samples were investigated by X-ray diffraction (XRD) (GBC MMA), field emission scanning electron microscopy (FE-SEM; JEOL JSM-7500FA) with an energy dispersive X-ray spectroscopy (EDS) detector and transmission electron microscopy (TEM, JEM 1200EX). X-ray photoelectron spectroscopy (XPS) was conducted with a SPECS PHOIBOS 100 Analyser installed in a 
high-vacuum chamber with the base pressure below $10^{-8} \mathrm{mbar}$, with $\mathrm{X}$-ray excitation provided by $\mathrm{A} 1 \mathrm{~K} \alpha$ radiation with photon energy ho $=1486.6 \mathrm{eV}$ at the voltage of $12 \mathrm{kV}$ and power of $120 \mathrm{~W}$. XPS spectra were recorded with a $20 \mathrm{eV}$ constant pass energy. The binding energy scale was calibrated using the $\mathrm{C} 1 \mathrm{~s}$ peak at $284.6 \mathrm{eV}$.

Electrochemical measurements. The S/SP composite was mixed with super $\mathrm{P}$ and poly (vinylidene fluoride) (PVDF) with a weight ratio of 80:10:10 in N-methyl-2-pyrrolidone (NMP) to form slurry, which was pasted on aluminium foil and then dried in a vacuum oven at $50^{\circ} \mathrm{C}$ for $24 \mathrm{~h}$. Sulphur content in a typical electrode is around $0.8 \mathrm{mg} \mathrm{cm}^{-1}$. CR 2032 coin-type cells were assembled in an Ar-filled glove box (Mbraun, Unilab, Germany) using lithium metal foil as the counter electrode. For the new configuration, a piece of graphite film was placed between the sulphur cathode and the separator. The electrolyte was $1 \mathrm{M}$ bis (trifluoromethane) sulfonimide lithium salt (LiTFSI) in a 1:1 vol/vol mixture of 1, 3-dioxolane (DOL)/dimethoxyethane (DME). Cell disassemble was carried out in the glove box; the sandwiched graphite film and the cathode were washed with DOL and dried at room temperature. The cells were charged/discharged at $168 \mathrm{~mA} \mathrm{~g}^{-1}$ using a charger system manufactured by Land Battery Testers. Cyclic voltammetry (CV) was conducted on a Biologic VMP3 electrochemistry workstation at a scanning rate of $0.1 \mathrm{mV} \mathrm{s}^{-1}$.

\section{Results and discussion}

For the cathode material, a new structure of S/SP composite was prepared. The sulphur in the S/SP composite was confirmed by X-ray diffraction (Fig. 1a) and Raman spectra (Fig. 1b). The two peaks at 1345 and $1604 \mathrm{~nm}^{-1}$ are assigned to Super P. As determined by Thermogravimetric analysis, the content of sulphur in the composite is $75 \mathrm{wt} \%$. The core-shell morphology of the composite can be seen from the scanning electron microscopy (SEM) images. The size of the composite is around $10 \mu \mathrm{m}$ (Fig. 1c), at the surface of which are linked nanoparticles of Super P (Fig. 1d). The linked nanoparticles have a diameter of around $40 \mathrm{~nm}$ (Inset). The S/SP composite is composed of the micrometer-sized sulphur particle as the core and the linked nanoparticle $(\sim 50 \mathrm{~nm})$ of Super $\mathrm{P}$ as the wrapping layer. We assume the contact coating of Super $\mathrm{P}$ improves the conductivity of the micrometer-sized sulphur particles.
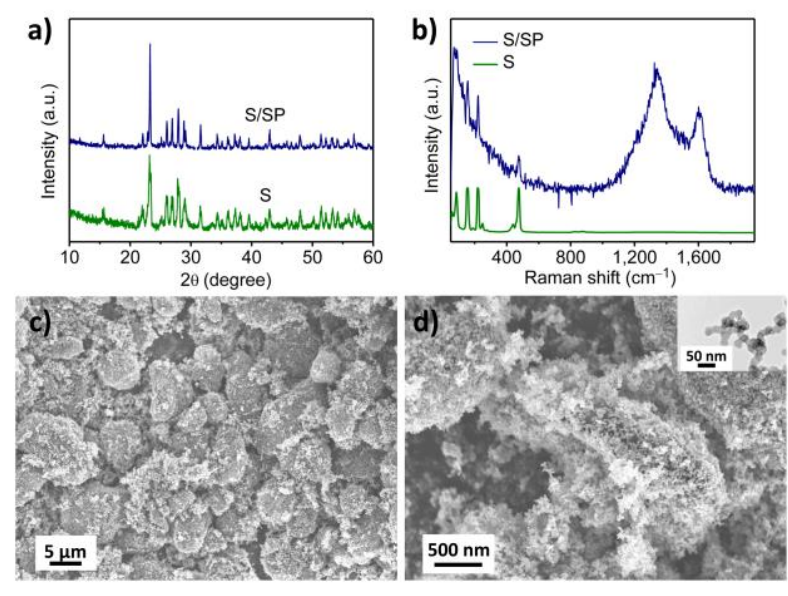

Fig. 1 Composition, structure and morphology analysis of the as-prepared S/SP composite. (a) XRD patterns and (b) Raman spectra of S/SP and sulphur. SEM images of S/SP composite at magnifications of $(c) \times 2,000$ and $(d) \times 30,000$. Linked carbon nanoparticles of Super $\mathrm{P}$ wrap around the micrometer-sized Sulphur particles. TEM image of Super P (inset).
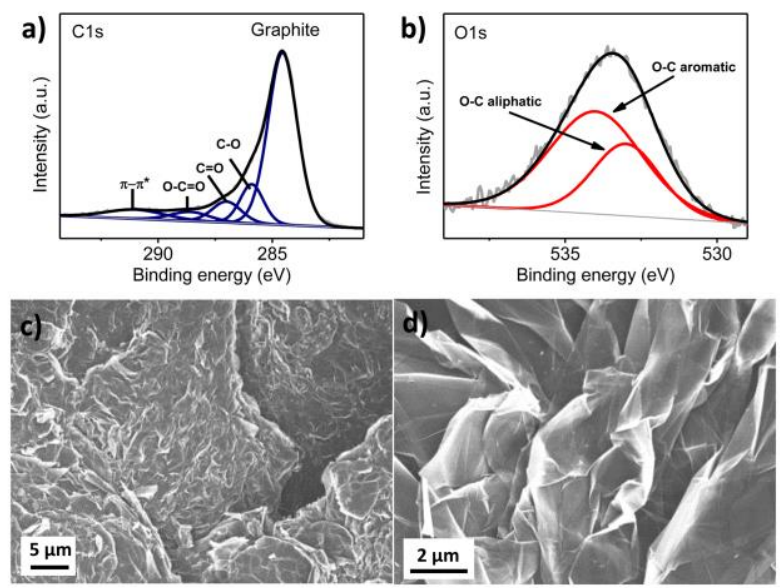

Fig. 2 Structure and morphology characterization of hydrothermally treated graphite film. XPS spectra for (a) C1s and (b) O1s peaks and fitting curves. SEM images of the inside of the graphite film at magnifications of (c) $\times 2,000$ and (d) $\times$ 10,000 .

The graphite film after hydrothermally treated was analysed by XPS and SEM. The XPS C1s spectrum of graphite is presented in Fig. 2a. The main peak at $284.6 \mathrm{eV}$ can be assigned to aromatic C-C bonds, and the broad low-intensity peak centred at $291.0 \mathrm{eV}$ corresponds to the $\pi-\pi^{*}$ shake up satellite ${ }^{11}$. Between them are the other three peaks, which are at 285.9, 287.0 and 288.6, respectively. It was reported ${ }^{12}$ that compared to the graphite $\mathrm{C} 1 \mathrm{~s}$ peak, single-bonded $\mathrm{C}-\mathrm{O}$, double-bonded $\mathrm{C}=\mathrm{O}$ and carboxylic $\mathrm{O}-\mathrm{C}=\mathrm{O}$ are shifted by $\sim 1.5 \mathrm{eV}, 3.0 \mathrm{eV}$ and $4.5 \mathrm{eV}$, respectively. It can be seen that the shifts for these three components match very well with these values. These organic functional groups are also reflected by the XPS O1s spectrum in Fig. 2c. The peaks at 533 and $534 \mathrm{eV}$ are assigned to $\mathrm{O}-\mathrm{C} s p^{3}$ and $\mathrm{O}-\mathrm{C} s p^{2}$ species, respectively ${ }^{13}$. These oxygen species might have been introduced into the graphite under the hydrothermal treatment. It is noteworthy that, during the 
charging and discharging of the modified cell, the organic functional groups on the graphite film might play a glue-like role in retaining sulphur and polysulphides ${ }^{14}$. Moreover, in the graphite film, there are evident cracks (Fig. 2c), which might have been introduced by the hydrothermal treatment. In the closed environment of the autoclave at $120^{\circ} \mathrm{C}$, a temperature above the boiling point of water, the water vapour might strongly interact with the graphite film and produce some channels in it. In another work ${ }^{15}$, a certain ratio of carbon black was mixed with reduced graphene oxide to form a free-standing paper for a new Li-S battery configuration, and the function of the carbon black was to produce channels, which enabled the transportation of electrolyte and lithium ions. As can be seen from Fig. 2d, the graphite film is composed of carbon nanosheets stacking with each other. The nanosheets behave as the reaction sites for the active sulphur species. a)
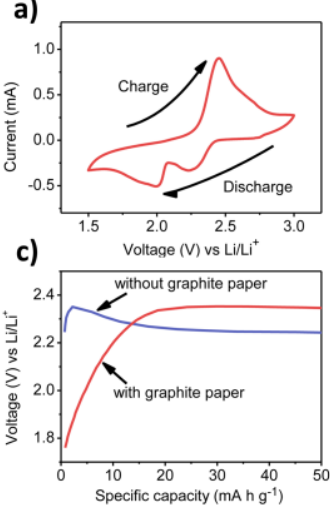

b)

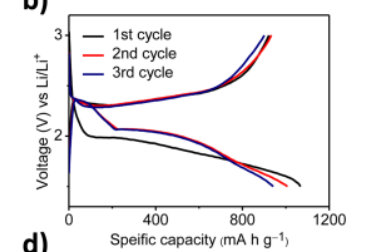

d)

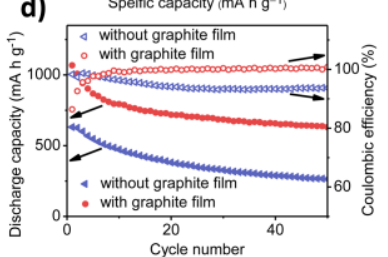

Fig. 3 Electrochemical performance of the Li-S battery with cathode material of S/SP composite and graphite film between the separator and the cathode. (a) A typical CV curve of the Li$\mathrm{S}$ battery with new configuration. (b) charge/discharge voltage profiles for the first three cycles of the Li-S battery with new configuration. (c) Charge voltage profiles at the beginning stage of the initial cycles for the cells without and with sandwiched graphite film. (d) Capacity retention and the corresponding Coulombic efficiency of the cells without and with graphite film.

The electrochemical performances of cells with and without a graphite film are presented in Fig. 3. Typical electrochemical reactions are revealed by the $\mathrm{CV}$ results (Fig. 3a). The cathodic peaks at $2.00 \mathrm{~V}$ and $2.23 \mathrm{~V}$ correspond to the two-step reaction from elemental sulphur to insoluble $\mathrm{Li}_{2} \mathrm{~S}_{2}$ or $\mathrm{Li}_{2} \mathrm{~S}$ through intermediate soluble polysulfides (e.g., $\mathrm{Li}_{2} \mathrm{~S}_{8}, \mathrm{Li}_{2} \mathrm{~S}_{6}$ and $\mathrm{Li}_{2} \mathrm{~S}_{4}$ ). The overlapping anodic peaks at $2.45 \mathrm{~V}$ relates to the inverse reactions, i.e., lithium sulfides are oxidized to lithium polysulphides and elemental sulphur. Initial discharge/charge voltage profiles for the first cycles present one discharge plateau at $\sim 2.0 \mathrm{~V}$, followed by a long slope (Fig. 3b). While for the following two cycles, there are two discharge plateaus: the first at $\sim 2.3 \mathrm{~V}$ and the second at $2.1 \mathrm{~V}$. The two cycles show high discharge capacities of 1008 and $942 \mathrm{~mA} \mathrm{~h} \mathrm{~g} \mathrm{~g}^{-1}$, respectively. It is noted that for the first cycle, the discharge voltage plateau is more negative than the following cycles. This phenomenon can be attributed to the affected electrochemical reactions between lithium ion and sulphur owing to the addition of the graphite film ${ }^{16}$. Further investigation is needed to unveil the exact mechanism. Moreover, compared to the cell without the graphite film, the beginning stage of the charge process exhibits a much lower polarization, demonstrating that the graphite film functions as a pseudo-substrate for the sulphur cathode (Fig. 3c).
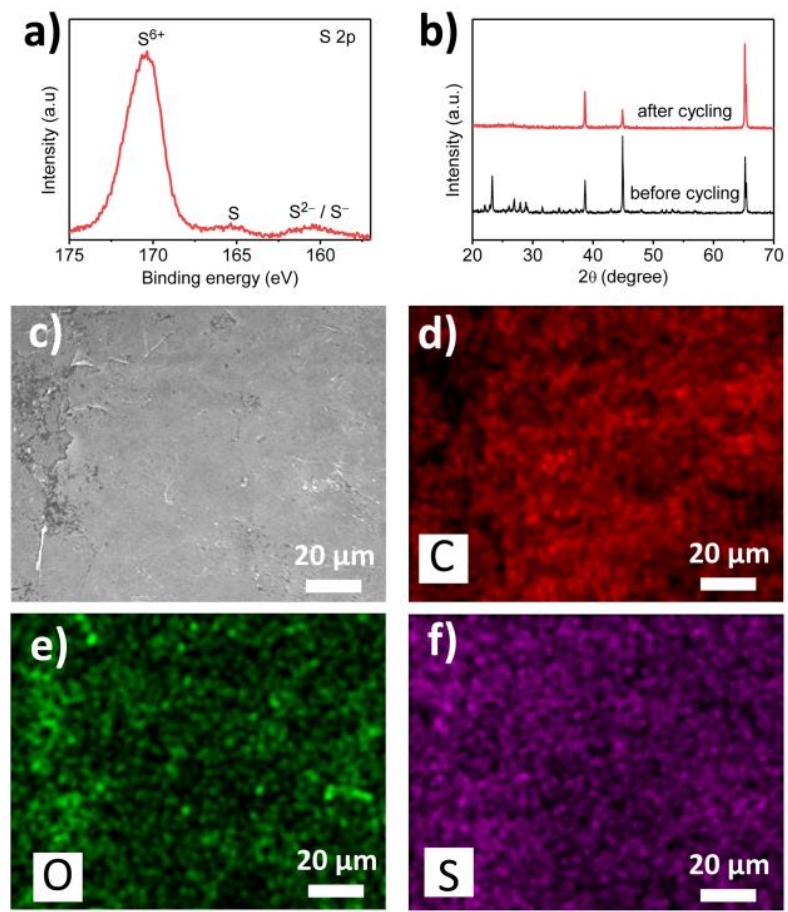

Fig. 4 Characterization of the cathode and the graphite film after charge/discharge. (a) XPS S $2 p$ results of the graphite film after charge/discharge of the Li-S cell. (b) XRD patterns of the cathode before and after charge/discharge. (c) The SEM image of the graphite film after charge/discharge and the corresponding XEDS elemental maps for (d) C, (e) O, and (f) S.

The graphite film enables much higher capacity, markedly decreased capacity decay and higher electrochemical stability (Fig. 3d). The cell with the graphite film exhibits a high initial

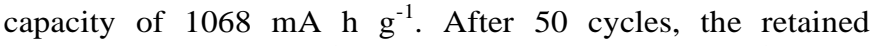
capacity is $631 \mathrm{~mA} \mathrm{~h} \mathrm{~g}^{-1}$, triple that of the $203 \mathrm{~mA} \mathrm{~h} \mathrm{~g}^{-1}$ for the cell without the graphite film. In order to exclude the capacity contributed by the graphite film, a Li/graphite film battery was assembled. The contribution from the graphite/Li+ intercalation process was $36 \mathrm{~mA} \mathrm{~h}$ per gram of sulphur, which takes place only ten percent of the whole improvement of capacity. It can be revealed that the graphite film only functions as a polysulfide blocking layer instead of an electrode. It is noted that the graphite/Li+ intercalation happens at a voltage below $0.2 \mathrm{~V}$, while the voltage window here applied is from $1.7 \mathrm{~V}$ to $2.6 \mathrm{~V}$. Also, the Coulombic efficiency of the Li-S battery with the new configuration stabilizes at near $100 \%$, compared to the 94\% for the conventional cell configuration. The improved Coulombic efficiency indicates that the sandwiched graphite 
film plays an important role in suppressing the polysulphide shuttling.

The function of the graphite film was further studied by disassembling the cell and examining the cathode and the graphite film using XRD, XPS, SEM and EDS (Fig. 4). After 10 cycles, the XRD peaks for sulphur disappear, with only peaks for the aluminium substrate remained, showing that the sulphur in the cathode has turned amorphous (Fig. 4a). Moreover, the XPS S2p spectrum shows three peaks centred at around 170, 165 and $160 \mathrm{eV}$ (Fig. 4b). The values of these three peaks match very well with the literature ${ }^{17}$, from which they can be assigned to $\mathrm{S}^{6+}$, elemental $\mathrm{S}$, and $\mathrm{S}^{2-} / \mathrm{S}^{-}$, respectively. The $S^{6+}$ species could be assigned to residue lithium salt from the electrolyte, while $\mathrm{S}, \mathrm{S}^{-}$and $\mathrm{S}^{2-}$ are ascribed to the products of the electrochemical reactions that take place on the graphite film. This observation proves that the graphite film locating between the separator and the cathode provides extra place for the electrochemical reactions in the Li-S battery. The sulphur species on the graphite film originate from the solvable polysulphides, that is, the intermediate products in the transformation between the end products of sulphur and $\mathrm{Li}_{2} \mathrm{~S}$ (Figs. 4c-4f). The polysulphides are retained by the functional groups in the graphite film. Hence, they can stay on the graphite film and be oxidized or reduced in the charge/discharge process. In this way, the graphite film functions as a pseudo-substrate, greatly enhancing the retention of active material, improving the capacity, electrochemical stability and cycling capability.

\section{Conclusions}

A hydrothermally treated graphite film was sandwiched between the sulphur cathode and the separator. The functional groups on the graphite film play an important role in retaining the solvable sulphur species. Owing to the improved utilization of active material, the specific capacity was significantly improved for the new configuration. The graphite film in the Li-S cell acts as a blocking layer against soluble polysulphides and provides additional reaction sites for the sulphur species. After 50 cycles, the cell with the graphite film retained a capacity which was almost triple that of the cell without the graphite film. Also, the Coulombic efficiency was increased from around $94 \%$ to near $100 \%$, indicating a much more stable Li-S battery.

\section{Acknowledgements}

The work is supported through Auto CRC 2020, project 1-111. We would like to acknowledge the utilization of facilities and assistance of staff at the University of Wollongong Electron Microscopy Centre. We also thank Dr Tania Silver for critical reading of the manuscript. 587-603. and J. Affinito, J. Electrochem. Soc., 2009, 156, A694A702; (b)A. Manthiram, Y. Fu, S.-H. Chung, C. Zu and Y.-S. Su, Chem. Rev., 2014, 114, 11751-11787.

3. (a)Y. X. Yin, S. Xin, Y. G. Guo and L. J. Wan, Angew. Chem. Int. Ed., 2013, 52, 13186-13200; (c)G. Zhou, D.-W. Wang, F. Li, P.-X. Hou, L. Yin, C. Liu, G. Q. Lu, I. R. Gentle and H.M. Cheng, Energy Environ. Sci., 2012, 5, 8901-8906.

4. S. E. Cheon, K. S. Ko, J. H. Cho, S. W. Kim, E. Y. Chin and H. T. Kim, J. Electrochem. Soc., 2003, 150, A800-A805.

5. X. L. Ji, K. T. Lee and L. F. Nazar, Nat. Mater., 2009, 8, 500506.

6. (a)M. Vijayakumar, N. Govind, E. Walter, S. D. Burton, A. Shukla, A. Devaraj, J. Xiao, J. Liu, C. Wang, A. Karim and S. Thevuthasan, Phys. Chem. Chem. Phys., 2014, 16, $10923-$ 10932; (d)G.-C. Li, G.-R. Li, S.-H. Ye and X.-P. Gao, Adv. Energy Mater., 2012, 2, 1238-1245.

7. (a)C. F. Zhang, H. B. Wu, C. Z. Yuan, Z. P. Guo and X. W. Lou, Angew. Chem. Int. Edit., 2012, 51, 9592-9595; (b)K. Zhang, Q. Zhao, Z. L. Tao and J. Chen, Nano Res., 2013, 6, 38-46; (c)J. Xu, J. Shui, J. Wang, M. Wang, H.-K. Liu, S. X. Dou, I.-Y. Jeon, J.-M. Seo, J.-B. Baek and L. Dai, ACS Nano, 2014, 8, 10920-10930.

8. (a)X. M. He, W. H. Pu, J. G. Ren, L. Wang, J. L. Wang, C. Y. Jiang and C. R. Wan, Electrochim. Acta, 2007, 52, 73727376; (b)W. Li, Q. Zhang, G. Zheng, Z. W. Seh, H. Yao and Y. Cui, Nano Lett., 2013, 13, 5534-5540; (c)L. Xiao, Y. Cao, J. Xiao, B. Schwenzer, M. H. Engelhard, L. V. Saraf, Z. Nie, G. J. Exarhos and J. Liu, Adv. Mater., 2012, 24, 1176-1181.

9. (a)Z. W. Seh, W. Y. Li, J. J. Cha, G. Y. Zheng, Y. Yang, M. T. McDowell, P. C. Hsu and Y. Cui, Nat. Commun., 2013, 4, 1331; (b)Q. Pang, D. Kundu, M. Cuisinier and L. F. Nazar, Nat. Commun., 2014, 5.

10. (a)Y. S. Su and A. Manthiram, Nat. Commun., 2012, 3; (b)M. R. Kaiser, J. Wang, X. Liang, H.-K. Liu and S.-X. Dou, J. Power Sources, 2015, 279, 231-237.

11. M. R. Cuervo, E. Asedegbega-Nieto, E. Diaz, S. Ordonez, A Vega, A. B. Dongil and I. Rodriguez-Ramos, Carbon, 2008, 46, 2096-2106.

12. M. Phaner-Goutorbe, A. Sartre and L. Porte, Microsc. Microanal. Microstruct., 1994, 5, 283-290.

13. J. L. Hueso, J. P. Espinos, A. Caballero, J. Cotrino and A. R. Gonzalez-Elipe, Carbon, 2007, 45, 89-96.

14. L. Wang, Z. H. Dong, D. Wang, F. X. Zhang and J. Jin, Nano Lett., 2013, 13, 6244-6250.

15. X. F. Wang, Z. X. Wang and L. Q. Chen, J. Power Sources, 2013, 242, 65-69.

16. J. Wang, J. Yang, C. Wan, K. Du, J. Xie and N. Xu, Adv. Funct. Mater., 2003, 13, 487-492.

17. E. Sosa, R. Cabrera-Sierra, M. T. Oropeza, F. Hernandez, N. Casillas, R. Tremont, C. Cabrera and I. Gonzalez, J. Electrochem. Soc., 2003, 150, B530-B535.

\section{References}

